\title{
On SSK and Conversing with Scientists: Eugénia Rodrigues Talks with Michael J. Mulkay
}

\author{
EUGÉNIA RODRIGUES \\ UNIVERSITY OF EDINBURGH \\ MiCHAEL J. MULKAY \\ FORMERLY, UNIVERSITY OF YORK
}

\begin{abstract}
Mike Mulkay takes Eugénia Rodrigues through a journey that revisits his involvement in the Sociology of Scientific Knowledge and STS. They talk dates, career moves, foundational work, books, and how it all started with a denied visa application from the US. Running under this formalistic level, though, other themes emerge: the notion of a "field" and its meaning in STS; the observed lack of epistemological and methodological rigor in research practice; Mulkay's unsuccessful (on his own account) project on the literary forms or his unfazed take on the work produced by the "Edinburgh School." It is a fascinating expedition and one that reveals some very present-day questions for STS, not least about the meanings of engagement and reflexivity. A reflection by Eugénia Rodrigues follows the interview.
\end{abstract}

\section{Keywords}

Mike Mulkay; interview; reflexivity; discourse; literary forms; rigor

\section{"Looking Around," "Finding Books," and Critiquing the Functionalist Approach to Science}

ER The first question is about your interest in SSK and STS, how did you become involved in this area? Where did your interest arise from, what made you do this instead of anything else in relation to sociology and social sciences?

MM I graduated from the LSE in 1965, with a clear intent to go to the University of Wisconsin and do work on small groups, because there was a big tradition of that kind of work in the United States at that time. That grew out of previous work by George Homans and others in the United States. But the American authorities refused to give my wife a visa so at the last minute I found myself unable to go to Wisconsin but with an interest in going somewhere else. My supervisor at the LSE, he had just left to take up the head of department at Simon Fraser University in Vancouver so I sent him a telegram saying,

: Eugénia Rodrigues, Email: eugenia.rodrigues@ed.ac.uk

Copyright (c) 2018 (Eugénia Rodrigues, Michael J. Mulkay). Licensed under the Creative Commons Attribution Noncommercial No Derivatives (by-nc-nd). Available at estsjournal.org. 
"Tom I've got a first class degree, would you take me on?" and he sent me a telegram back, "yes, come immediately." So we sold all our books, went to the Canadian Embassy and got an assisted passage to Vancouver. So I found myself in a new university where they were just creating a new library from scratch, they'd been looking around for good books and they had a supply of all the things recently published, and I was there as a teacher but also looking around for something to study to do an MA thesis on. How I came to choose science I really don't know but certainly the two books that influenced me, I must have just found them easily available in this new library, were Thomas Kuhn's The Structure of Scientific Revolutions (1962), which I found engrossing, and a reader called I think probably The Sociology of Science by Bernard Barber and Walter Hirsch (1962). Those were the two texts that I drew upon in designing an MA study, and I did an MA study which looked historically at the development of science in relation to social institutions and then a small piece of empirical work on the student body at Simon Fraser to show how they had come to choose science as their subject of study. So that's how I got into it, why I chose that one, was it just that I saw those books or did I have a prior interest in science, I don't know, but that's how I got into the field. Do you want me to continue to tell you what I did?

ER Yes, that's exactly right, please continue. I have wondered whether you have approached your interest for science as a research area from within the context of criticizing the functionalist analysis of science, I'm not sure if you want to think in these terms.

MM I don't think that was on my mind at that stage. One of the reasons I probably chose science as a topic of study was that I had read American literature which treated sociology itself as a science. So I came from within the scientific tradition and the big long-term attempt from Durkheim and others in the European tradition, and Parsons and Homans and so on in the American tradition, who thought sociology was going to become the science of society. I suppose it was there in my mind that science somehow was the big cultural event of the $20^{\text {m }}$ century, it was the form in which knowledge now made itself evident. Why not look at it because it is so culturally important? and those two books that I mentioned were the avenues through which I got into or became familiar with the literature that treated science as a subject of study, rather than just as a background framework for one's own work. What I did then, the work on students' choice of science, I wrote up as a very traditional quantitative study of scientific recruitment which I then published in one of the Canadian journals; there were two major journals, I can't remember which one it was but in one of those I published this material within a year or so of finishing, that would have been probably 1966 or '67, so as a first publication. I then wrote a long and rather rambling article, which I got accepted by Sociological Review in New York. So I was learning about science but I was also learning how you got things published as a social scientist, all of this was new to me. And then I did a study of the physics department at Simon Fraser, which I really enjoyed because I came to know the physicists. There was a group of, the entire department was solid state physics. Again, this was probably based upon some of the studies in the 
Bernard Barber reader where they took a segment of the scientific community and tried to look at it in detail, so I tried to do that with the solid state physics department. Those are the three things I did while at Simon Fraser, the recruitment of scientists study, the study of the physics department and this long rather theoretical article, deriving in large measure from having read Kuhn and then just looking at the other literature, the sociological literature, and finding it inadequate. I think at that point I began to think the Mertonian sort of approach, the functionalist approach to science was in no way satisfactory and didn't seem to have good evidential base, so I developed the beginnings of a critique.

\section{Interrogating the Origins of a Field}

MM That article was clearly found by Barry Barnes at Edinburgh, because he published it a few years later in a reader of his own (Barnes 1972), where he put things, as many articles as he could find that had some relevance to what eventually became known as SSK. So he must have noticed it but it took a lot of time to get published that one. I remember I left it for two years waiting for them to publish it and then I had to write to them and then eventually they did actually publish it. I wrote it in '66-67 and it probably got published in '69-70, by which time I was back in the United Kingdom. Shall I just carry on?

ER Yes, please. I was also interested to know a bit more about how you see the origins of the field, SSK and STS, or maybe SSK first and then STS. I don't know how you position these two areas, if they are one and the same or how you see them.

MM At that time I didn't think of myself as being part of a field because I knew nobody personally who was working on science, I was doing it in complete isolation. I knew there was a, it was possible to produce a book like the Barber and Hirsch which brought all these articles together but none of these articles really focused on the kinds of issues that I was interested in, particularly in the more theoretical article that I had written, it was much more influenced by Thomas Kuhn and his writings. As far as the field was concerned I would have said I was in the same field as Thomas Kuhn, but I didn't know of any other sociologists, not personally, I only knew them from the Barber and Hirsch collection. The idea of a field called SSK or even STS, neither of those terms would have had any meaning for me at that time. The first time I came to think that there might be other people around doing something similar was when I came back to the United Kingdom, and I went to the University of Aberdeen from 1968 to 1970. During those two years I concentrated on writing my PhD thesis on sociological theory. I did no work on science. However, I was contacted by people who wanted me to attend a little conference somewhere, I think it was from Manchester. I can't remember who got in touch with me but the man that I met and noticed most at that meeting was Richard Whitley, I don't know if he's on your list of interviewees, he ought to be because as far as England or Britain was concerned Richard Whitley was really quite important at that time. He continues to publish in the area and wrote quite a good book on SSK and related issues 
later on. He invited me to this meeting at Manchester and there I realized there were other people (whose names I've now forgotten). Richard is the only person I can remember. There seemed to be a little coterie of people, all men entirely, there were no women involved in the field at that time, in Britain, who seemed to be interested in the kind of work I'd been doing in Canada. Then I suppose you could say I had some sense that there might be a field and that there were actual real people out there doing work.

ER I guess if you had to pinpoint the origins of that field, those key books, Kuhn and Barber and Hirsch would be the foundational work, as far as you are concerned?

MM Yes, in that very early stage.

ER Then, later, you mentioned Barry Barnes who wanted to publish that other article, would there be any other published works or conferences? You mentioned Manchester. Those would have been the key elements at the time from which an area would have emerged I guess.

MM Yes, in the 1960s I didn't know of the Edinburgh group and I really can't remember when I first became aware of them. I clearly had met David Edge by the time we'd worked on the radio astronomy.

ER We could perhaps move to the Edinburgh School then.

\section{Edinburgh}

MM Clearly they became an important element in the British scene because they were organized as a science-only focus, and as far as I know there was nowhere else in the country at that time which had that kind of focus. I'm trying to remember when, I think we published the radio astronomy book...

ER In 1976, I believe.

MM I was in Cambridge from 1970-1973 so it was during that period that we did all the work on radio astronomy. In fact I chose, I got to Cambridge in 1970. I decided for reasons I cannot remember to try to study radio astronomy as an area of investigation. Clearly by that stage I'd got the idea of focusing upon particular scientific networks as the focus of my work, and how they produced knowledge. Clearly I'd had a kind of definition of what you might call SSK as an area of work but I still don't think I was thinking of myself as part of a field, but that's the kind of work I was going to do. Then David Edge got to hear of this and contacted me and said, "I was a radio astronomer, why don't we do it together?" and I jumped at that opportunity because he knew the field, he knew the people and did all the hard work of finding out who the people were and getting their permission and their interest, all of that was done through David.

ER Perfect partner it seems. Your relation with Edinburgh, I guess, is pretty much circumscribed to the work that you developed with David Edge, or is there more?

MM No, I had no contact with Edinburgh. My contact with Edinburgh was almost entirely with David really rather than Edinburgh. 
ER Could you reflect a bit more on that; despite that disconnection I guess you were aware of the work that was being done in Edinburgh?

MM Yes, I was aware of the publications that came out, and the journal of course.

ER Could you reflect then on the role of the Science Studies Unit in the development of STS as a field? For instance, what sort of influence would the Unit have had and what would you say were its main contributions to the field in terms of methodologies or theories?

MM I don't think that the... Barry Barnes published a theoretical book at that time and David Bloor must have published other things before his Strong Programme stuff. For me these were not important influences, I'd already worked out what I thought I wanted to do, what the interesting issues were and how to go about doing it, I got involved in the empirical work with David. I didn't see interesting empirical work coming out of Edinburgh, I felt they were theorizing, and I more or less broadly agreed with their approach but it didn't influence me a great deal because I'd already come to those conclusions. Those conclusions, by that I mean the idea that scientific knowledge was itself a cultural product, not intrinsically different from other cultural products, and it could be studied in much the same way. If that's the essential insight of SSK then I'd reached that conclusion years before when I was in Vancouver, and I didn't find the kind of broad theorizing that seemed to me to be coming from Edinburgh terribly helpful. Partly because my first book as a sociologist was a critical consideration of some sociological theories and the broad conclusion I came to in that book was that these theories were too far removed from what you might call the real world and when you try to apply them to real world instances you couldn't get any grasp upon them. I did think that the Edinburgh group was a bit like that in relation to science. That's a partial view, not everybody thought that way and probably many people did do empirical work that was linked to it. Anyway, that was I guess my broad feeling about Edinburgh.

ER That's very interesting. In terms of the subsequent development, in terms of the contribution of what is now called the Edinburgh School, a term which itself can be contested--I don't know if you want to say anything about that--do you see a contribution to the field itself from these people in Edinburgh? Thinking more broadly, do you see places where the work that was developed in the Science Studies Unit has made an enduring contribution to the field, or not that much?

MM It may have done but you have to realize that I've been out of the field for a long time and not thought about it at all, so it's not something that's anywhere near the surface of my mind. I don't know how one would assess that kind of contribution to something called a field. We know that the very notion of a field is itself a kind of creation, a convenient device for doing something, for doing some research or whatever, or making sense of the world temporarily. I've never really thought about being in a field very much, or making a contribution to a field so I find it difficult to assess other people's contribution. 


\section{STS and Other Matters}

ER That's fine. Let's try to move to another topic. I know it, and you've said that you've been retired for some time now, but if you think of, up to the point that you were actively involved in the field, could you reflect on the trajectory or development of STS up to that point? For instance, major works; what aspects were particularly meaningful to you? Do you have that sort of broader view of STS and SSK? Since your first steps, what do you think has happened to STS and SSK?

MM I guess that my own trajectory was to move away from thinking about...I guess the issue that became significant for me was the unwillingness of SSK to apply its own conclusions to itself. So I suppose I was thinking a bit as a field in that sense, that there were a number of people doing SSK, drawing these conclusions about knowledge producers in what we call the sciences, and those conclusions seemed to me to be necessarily applicable to SSK itself. But very few people wanted to make that leap and think, "does this have any implications for us at all?" I guess it was a safe conclusion because nobody wanted to upset the scientists. There were some points in the later years where scientists became quite irritated and there were public debates in which the scientists tried to protect their area from this kind of defamation that the sociologists seemed to be offering. So there's reasons for suggesting, "yes science is like this, just like any other field but don't worry it doesn't have any consequences for you, carry on doing what you're doing exactly as you're doing it." It seems to me, I just felt unhappy with that kind of view. It does have, if it's the way we think it is then it does have consequences, it does have-you do need to think about the kind of practice that you're involved in. We ought to be saying that to the scientists and equally we ought to be thinking about it for ourselves. So I think I became particularly concerned with and interested in that kind of issue rather than with the more traditional, conventional work that was being done in SSK. I think that I'm probably the last person to try to offer an assessment of what SSK was doing or how it was developing as a field. I guess it probably changed quite a lot when Latour became an important and influential figure.

ER I was going to ask if there were any turns or key figures that would mean a change of direction in some way, so you identify Latour, yes?

MM Clearly there was that work with Knorr-Cetina and Latour, and probably other people as well, who went into laboratories in the way that they suggested an anthropologist might go into a tribal society and study it, the real things going on in the laboratory. I guess that was a big step or became quite influential and then led to Latour's book, which incidentally I read for the publisher and recommended for publication so I must have thought it was pretty good. But again his work didn't really influence me in any significant way. 


\section{...on Being Disillusioned}

ER If we think of your own work, the idea or key aspects that you developed in your analysis, for instance, the analysis of scientific discourse or the new literary forms, and reflexivity, how do you see your work in relation to the other types of work that were being developed and implemented?

MM I should think it was almost entirely ignored by people doing the other work, so I imagine it's had no influence at all, that would be my guess.

ER You didn't see it being followed by others?

MM I think it must have been The Word and the World (Mulkay 1985), which I really liked as a book, I thought it had some nice things in it. I asked David why there had been no reviews and he said nobody's willing to read it.

ER Why do you think that was?

MM I guess it's that defensiveness in relation to self-reference, it's an unwillingness to look at one's own practice, what is the point of doing that seems to be the... And it seems a bit frivolous doesn't it? These sort of dialogues, messing about and playing games, which is probably true. I think I might have become disillusioned with the whole enterprise by that stage and just was becoming playful. So I can understand why it was hidden away.

ER I wouldn't say it was ignored at all, if I may express a view about that.

MM If it hasn't been ignored then that's great but I have no knowledge of how it might have been influential.

ER Like any other field or any other area (let's talk about academic disciplines, that's probably the most correct and straightforward way to avoid the idea of the field) STS has been influenced by political commitments, by social concerns and so on, which would you say were the most important ones in the area of STS? Or for you personally.

MM I can probably talk personally, I don't know. I've not seen myself as having been influenced by external considerations at all. That may be quite untrue and we're often quite blind to the things that influence our actions and the things that influenced our beliefs but I'm completely unaware of having been influenced in that way. I've simply followed my own intellectual interests and these have been quite often influenced by the students that I've had around me, they've all influenced me, or influenced my thinking but in what ways I can't really pin down. So as far as I know, after that initial decision to work in this kind of area, the focus of my work has always been on, "what did I learn from the last study that I need to take into account in the next one?" I was always interested in some kind of empirical foundation, linking whatever I was doing to things which I thought were going on in the scientific community, rather than theorizing in abstract ways about them. So I think that was my guiding kind of principle.

\section{... and Moving on to Discourse Analysis and Reflexivity}

MM Quite often the particular areas of study came up by chance, the work on oxidative phosphorylation that led to Opening Pandora's Box (Gilbert and Mulkay 1984), that grew 
out of my knowing one of the professors of biology, then he was a senior lecturer in biology, who said, "this would be an interesting area for you to study, they're probably going to award a Nobel Prize for it." So I read up on it, thought it seemed interesting and got into that particular area of research in that way. In doing that work I came to the conclusion, for me this was a fundamental change in my understanding of SSK as I was trying to practice it. My conclusion in doing that work was that I could not use, the closer I looked at empirical material, the more careful and detailed I tried to be with that material, the less was I able to build up the kind of version of what was going on in the field that was essential to the traditional kind of SSK. The more careful you were, the more rigorous, the more you worked hard at dealing with the complexities of the material, the less it became possible to give versions of the field in the way that sociologists traditionally did. The essential problem is that any segment of social action is always open to alternative, equally viable, interpretations. And it was that kind of insight or feeling or mistake that led me into thinking of discourse analysis. I felt you could look at a particular text, and you could reasonably well describe the structure of that text so if somebody was accounting for somebody else's error, you could see a particular kind of pattern which became evident in any number of people accounting for other people's errors, or indeed even accounting for their own errors. But you couldn't go through that and look at the essence of what they were really doing in their actions in that field. You could look at the superficial content of their accounts but you couldn't go beyond those accounts by looking at other accounts, other documents and other data, put it all together to produce your own version of what was really going on, what I came to call a definitive version. Again I should have written much more about definitive versions than I did. I wasn't careful and systematic, careful enough about that as I should have been. Anyway, for me that was a really big insight and it was that which led me towards a concern with reflexivity and things of that kind. That was what I felt was the failure of traditional understandings and that failure was built around, in my view anyway, a failure to do empirical research carefully and systematically. When I looked at some of the work being done in the field I was horrified to find how they'd used some of the recorded data. I don't want to name any names, but there were people whose work I'd regarded as quite significant, and influenced my own work, who recorded interviews but didn't transcribe them, they just went back looking through for the passages which they thought fitted their particular interpretation. When I discovered that that was being done I could not believe that people hadn't transcribed everything and then gone carefully through it.

ER That's very telling. So that's having a kind of rigor, it's equivalent to having an ethic towards the material you've got, that you have to treat it the way it deserves, I guess.

MM Yes. I remember when Malcolm Ashmore came as one of my students, he asked me why did I have this ethic, it's a kind of Puritan ethic, what was the justification for it. He would always do that, simply arguing as a devil's advocate on any subject whatsoever, given the opportunity he would challenge the basis of your assumptions. And he's quite right, I had no idea where that came from. It's clearly present in the first book on 
sociological theory, which was very much along the same lines there. I found in that book all these sociological theorists to be wanting on the grounds that they simply hadn't been careful enough, rigorous enough in testing their theories out against the empirical world that they were supposed to be explaining. You could say for big sociological theories that they'd become too grandiose in their ambitions, they'd been much too premature, and you could understand why they got it so badly wrong because they were doing such a big, what they regarded anyway, as such a big important thing. But for sociologists of science looking at one relatively small empirical topic area, and then focusing in upon one research area within that domain, there is no excuse whatsoever for doing your work in such a shoddy fashion. That was a crucial moment in my career. I remember Nigel Gilbert and I worked on that study and Nigel, I've great admiration for Nigel but I don't think he actually went along with me in the rather extreme way in which I reacted to these problems. I don't think Nigel actually saw the problems with the data in the way that I did. He was very influential in producing the final text of that book but I think most of the book is me thinking through the problems that I saw with that material.

ER Very interesting. In relation to that book with Nigel, and the work you developed in collaboration with biologists in York that led to Opening Pandora's Box (Gilbert and Mulkay 1984), I was wondering whether you could reflect on the position of STS in relation to other core groups concerned with science and technology based on your own experience. They could be the scientists themselves or institutions or the policymakers...also you had this very close work developed in York in relation to the embryology project. Could you reflect on the sort of relations that STS established with other groups that had an interest as well in the practice of science and technology?

MM Again I'm not very clear upon what was done in other places and what happened in other universities for other researchers. I always felt that it was important to maintain good relationships with the scientists, not because that would help you to do your research but simply because they were interesting people with their own ideas. So at York we had regular discussion groups with members of the science departments and philosophers and people even from the English department, where we used to meet regularly and talk through various kinds of issues related to science, and I always found that very helpful.

\section{On the Way to Closing the Door}

MM That really is what I, in the long-term, had hoped that SSK would be able to establish on a much wider basis, that kind of friendly conversing with scientific practitioners. I thought it was also part of the, seemed to me to grow out of the reflexivity project, that the reflexivity was concerned with allowing different versions of social practice to coexist and to intermingle, and people with different views and attitudes and voices might be able to learn from each other without the kind of dogmatism that's often associated with the presentation of science and other forms of knowledge. It did work for a while at York 
and some of the people that I knew had never had a direct input into the research but they were indirectly there while I was listening to them and they were listening to me, and to various other people in the university. So that's the kind of conversing that I would like to have seen but I found the sociologists, as it seemed to me, to be really unwilling to listen to what I had to say about reflexivity. I guess I gave up any hope that that would become characteristic of the field at large. For me it would have been a good outcome if that had developed, and it may have developed, maybe it's truer to Edinburgh now. Clearly Steve [Yearley] has all sorts of contacts of that kind so it may well be that that kind of dialogue is going on but if it is then it's not evident to me, partly because I've been so long out of the field now. But it didn't seem to me to be happening very much when I was present in the field. The last project I did was one on embryo research and I've no idea whether that had any kind of impact but again I chose that topic because it was drawn to my attention by the biologists and I thought it was worthy of study because it had these kinds of, it had a social significance that grew out of the very nature of that material. And it wasn't a pure science subject but really it was an examination of how lay people, particularly members of parliament and so on, reacted to scientific issues. You saw there how the fundamental lack of understanding of science was so crucial to the way in which they approached; I didn't really discuss this in the book but one noticed how they were so dependent upon the scientific lobbyists. Let me put it this way, those in favor of embryo research were utterly dependent upon the stories told to them by the scientists. Clearly there were a large number of people who were utterly opposed to this kind of research, and they did not depend upon the scientists but they couldn't answer them, they had no way of dealing, when the scientists said, "this kind of research is fundamental to our understanding of medical trauma of various kinds, inherited disorders of all sorts will be solvable if you allow us to go ahead with this." They didn't agree, or they didn't want to believe it but they had no way of handling it. So the debate on either side, either those for or against embryo research, their level of understanding of science as a cultural enterprise was so minimal that the debate never really, it just seemed too impoverished. My book was an attempt at least to throw a little bit of light on that. One felt, yes there is an important project here which STS and SSK could be a big part, and for all I know they are increasingly a big part but I have no direct knowledge of that. You will know that much better than I do.

ER I think we are getting to that point where we are more involved.

MM I don't know a lot about Brian Wynne's work but I thought he always had that as part of his project, that kind of interplay between the kind of work he did and the scientists and the wider community.

ER Yes, I think it's increasing still.

MM But it's still on the margins isn't it, or is it not?

ER In many cases, I guess.

MM That big debate...

ER It's difficult to actually implement, I think. 
MM It's difficult to implement, partly because you have to allow other people to disagree with you so much, true dialogue has to allow that. It's so irritating when other people don't agree, especially when you know you're right.

ER My last question is, I guess you've said something about it, indirectly you've answered it but it's really about when you left York, when you retired from an active academic life and all that, where did you see STS and SSK going? In part I guess you've said it when you were talking about the idea and project of reflexivity not going the way you would have liked, but what else...

MM I didn't think it was going any way.

ER What else can you say about that or what else would you like to develop some more? Up to the point you were involved, where did you think SSK and STS were going? Were you happy with it? Were you disappointed? Were you feeling the vision that you had, if you had had a vision for SSK and STS in the past, how did it come about when you retired?

MM As you say, if I had a vision it was that vision of dialogue that I was referring to a little while ago, a kind of grand dialogue, it always seemed to me a possibility a grand dialogue about science, to which STS/SSK would contribute. But I guess by the time I retired it didn't seem to me very likely that that was going to happen, ever, or even on a small scale or more than just the odd corner of the academic world. Towards the end, I know what happened, I worked so hard on the embryo research study. I worked on that day after day for three years, trying to apply all the demands of rigor and careful research that I was talking about earlier to my own work, and I just felt at the end of it that I couldn't do any more. So I think I published that in 1998 and retired two or three years later. I think I just stopped at that stage, so I had no great feeling about where SSK or STS were going or whether the ambitions that I'd had for this intellectual enterprise had succeeded or not, I just closed the door, I left all my books in my office and locked the door and walked away. It was a very subdued note on which I left the department but one's life is divided into these sort of periods where one thing is dominant and then you stop it and do something entirely different. I'm quite proud of the period when I was a gravedigger on the south coast of England but as soon as I stopped digging graves I no longer thought about it, but essentially I did the same to my academic life although I did it for many more years, probably 30 years instead of just a few. I stopped thinking about it really until today. Occasionally Malcolm Ashmore comes, once a year and we talk about things but we don't really talk about SSK, we might talk about reflexivity because that's a different kind of focus. I don't know if that's an answer to the question but I've just done other things since then.

ER That's great, thank you very much, I really appreciate it. 


\section{Afterthoughts}

\section{BY EUGÉNIA RODRIGUES}

I met Mike Mulkay on one of those unique sunny winter days that Yorkshire can greet us with, when apparently all external factors align to produce something of an extraordinary order. This seemed to fit the occasion very well as I was about to interview one of the most influential authors in the sociology of scientific knowledge (SSK) and science and technology studies (STS). I attributed special meaning to this as, with a $\mathrm{PhD}$ in Sociology from the University of York (where many of his key works originated), I felt an acute responsibility and excitement towards this project.

The interview did not disappoint. Retired since 2001, Mike Mulkay has devoted his new life to basketry, an activity to which he has applied--as I could testify-some of the key principles that guided his academic and intellectual life: rigor, reflexivity, and methodicalness. His works are beautiful and display a complexity that can only be the end result of a systematic, accurate, and deeply intellectual approach. Regular "folk basket-making" it is not.

Mulkay retired in an unusual fashion. Having felt he had done all he could in pursuing his own epistemological and methodological "program," a sense of disillusion perhaps accompanied by some weariness and a certain degree of exasperation made him "close the door" without looking back after the research that led to the 1997 book The Embryo Research Debate: Science and the Politics of Reproduction (Mulkay 1997). Again, this is the sort of decision only available to a few: those who have "given it all" with an unflinching commitment from the outset.

This is very much in line, it seems to me, with one of the key aspects that characterized Mulkay's work alongside the rigor of his approach: his independence and autonomy. More than once in the interview, Mulkay talked of his theoretical independence, of not seeing himself--his work-as being associated with a field, of how little his work was influenced by others (with exceptions reserved for his students, some mentioned in the interview). It is even possible, at points, to detect a (one may wonder if cultivated) tendency to isolation. It is, conceivably, a delicate balance between a sense of entitlement and detachment that allows him to leave with no strings still attached. The same can be said about the way Mulkay evaluates his own influence in SSK and STS. His words are cold and severe: "I should think it [his work] was almost entirely ignored by people doing the other [constructivist] work, so I imagine it's had no influence at all $(\ldots)^{\prime \prime}$ This assertion, irrespective of whether one reads it as merely rhetorical or as representing Mulkay's take on his experience as part of an academic system, has wider ramifications. Clearly, the way one goes about doing and being a social scientist has changed dramatically in the decades that have elapsed since the young Mulkay started his own personal scientific endeavor. Research funding comes with (too?) many conditions attached, universities impose their own performance indicators, policy-linked research "trends" influence individual agendas, and to say that researchers exert their autonomy and individual agency in the scientific realm is something of a hyperbole. Present-day researchers can also face issues of job insecurity which add to a sense 
of an inescapable career treadmill that accentuates dependency at all levels. These developments in the occupational culture may even help to explain why STS scholars have apparently not been much interested in taking up Mulkay's favored critical-reflexive outlook for their discipline.

The influence of one's work can be gauged in many different ways. However one assesses it, it is hard to deny that Mulkay's influence endures. His pioneering work and role in the area of SSK and STS can hardly be contested as a quick search on Google Scholar (whatever its limitations) will attest. That he carried out this work without being affiliated to one of the emerging strands of thought (such as the "Edinburgh School" or the Bath group or even the German Finalizationists) may have contributed to it becoming less visible than would otherwise have been the case. That he voiced blunt criticism concerning the lack of methodological rigor he could observe in key work being produced at the time (see Mulkay 1981) might have deepened the sense of isolation. Finally, that he believed the principles and conclusions sociologists of science were arriving at on the social production of knowledge should be applied reflexively to SSK/STS may have distanced him further from his peers. All these aspects help to "situate" Mulkay's work but do not deny his fundamental role in the formation of SSK and STS.

Mulkay published extensively, the subject of his publications ranging from sociological theory, ${ }^{2}$ to reflexivity, ${ }^{3}$ and new literary forms. And, in a nice irony relating to Mulkay's claim about the lack of reviewers for The Word and the World, I did find (with little effort) a review published in the American Journal of Sociology by Donald N. McCloskey (1987). McCloskey asserts:

He [Mulkay] has invented a new form of discourse, the postmodernist novel melded with sociology. And a charming novel it is. The Book (...) analyzes in detail a dispute between two biochemists named "Marks" and "Spencer." ("Spencer" is Peter Mitchell, who in 1978 won the Nobel Prize in chemistry for the work under dispute.) The main subject, however, is sociology itself, the sociology of science in particular, and most particularly that "strong programme" advancing through British sociology of science in recent years, of which Mulkay leads a brilliantly literary wing.

Playful? And why not? Frivolous? ${ }^{5}$ I would not rush to classify this work as such. Playful texts clearly irritated some readers and others found it hard to pin down exactly what Mulkay was arguing for. But the playfulness seems to have been mostly aimed at keeping knowledge and certainties "in play" and finding dynamic ways to imagine and address the making and unmaking of knowledges.

Worth noting is, possibly, McCloskey's view on Mulkay leading a "wing" of the "strong programme." Though the term is used in a generic fashion, it is nonetheless a statement that

" The theory of SSK in, for example, Science and the Sociology of Knowledge (Mulkay 1979); case studies in SSK/STS in books such as Astronomy Transformed: The Emergency of Radio Astronomy in Britain (Edge and Mulkay 1976); Opening Pandora's Box: A Sociological Analysis of Scientists' Discourse (Gilbert and Mulkay 1984); and The Embryo Research Debate: Science and the Politics of Reproduction (Mulkay 1997).

${ }^{3}$ See Sociology of Science: A Sociological Pilgrimage (Mulkay 1991).

"See The Word and the World: Explorations in the Form of Sociological Analysis (Mulkay 1985).

s Playful and frivolous are words used by Mulkay to try to explain why this work has, apparently, been ignored in SSK and STS. 
locates Mulkay in a place he perhaps would rather not be. Mulkay's comments on the work carried out by his colleagues at the University of Edinburgh are demure: "I didn't see interesting empirical work coming out of Edinburgh, I felt they were theorizing and I more or less broadly agreed with their approach (...)"; "If that's the essential insight of SSK [the idea that scientific knowledge was itself a cultural product] then I'd reached that conclusion years before when I was in Vancouver, and I didn't find the kind of broad theorizing that seemed to me to be coming from Edinburgh terribly helpful." The implied targets of Mulkay's criticism are probably not hard to guess at, and it is noteworthy that (for example) interest theory, the focus of so much work in the 1970s and early 1980s, is now pursued by hardly anyone in SSK, at least not in its original form.

Less guess work is required when it comes to his thoughts about the "conversations" with scientists at the University of York. Was Mulkay's work and vision for the field ahead of his time? His hope, as expressed in the interview, that "SSK would be able to establish on a much wider basis, that kind of friendly conversing with scientific practitioners" is but a vision for the way in which the sociology of science might work and have what is today called "impact." Which may be ironic, given that Mulkay's notion of dialogue between researchers and scientific practitioners would emerge naturally out of the reflexivity project. That reflexivity can be connected in this way to "impact" is perhaps an unexpected outcome, one that Mulkay may find is a step in the wrong direction.

Mulkay's legacy is unquestionable. His emphasis on scientists' "talk" or discourse as the core empirical focus for STS work is clearly still widely accepted (and referenced), while his work on reflexivity and new literary forms has pushed the epistemological boundaries of this field of knowledge, testing its limits, experimenting and creating, in short, exemplifying what sociology is about: re-thinking the social order. It may well be intricate in parts, but not as much as his basketry.

\section{Author Biography}

Mike Mulkay is a renowned sociologist of science and one whose work had a decisive role in the foundation and development of SSK and STS. Mulkay began his career at Simon Fraser University in 1966, later moving to the University of Aberdeen, thence to the University of Cambridge and, finally, to the University of York where he was awarded a personal chair and stayed until his retirement in 2001. Mulkay published extensively and is perhaps best known for his work on the discourse analysis of scientific culture, work which he published in influential books such as Opening Pandora's Box: A Sociological Analysis of Scientists' Discourse (co-authored with Nigel Gilbert 1984) and The Word and the World: Explorations in the Form of Sociological Analysis (1985) as well as in numerous papers in Social Studies of Science and other journals in the 1980s. His later publications focused on the science and debate around the human embryo, culminating in the book The Embryo Research Debate: Science and the Politics of Reproduction (1997). Mulkay was the recipient of the J.D. Bernal Prize from the Society for Social Studies of Science in 1986. He lives in East Yorkshire and is a basket weaver. 


\section{Author Biography}

Eugénia Rodrigues is a lecturer in Science, Technology and Innovation Studies at the University of Edinburgh and educated at the Universities of Coimbra (Portugal) and York (England). She studies contemporary manifestations of participation and public involvement in science and scientific knowledge, such as the so-called citizen science phenomenon. She often links this interest with two other areas of research: social studies of monitoring (investigated both at the level of policymaking as in the case of climate change targets and of the individual practices as in self-tracking behaviors); and environmental and climate-change issues. Her publications include: Knowing New Biotechnologies. Social Aspects of Technological Convergence (co-edited with M. Wienroth, 2015) and "Policies, Politics and Organizational Problems: Multiple Streams and the Implementation of Targets in UK Government," Policy \& Politics (Co-authored with C. Boswell, 2015).

\section{References}

Barber, Bernard and Walter Hirsch. eds. 1962. The Sociology of Science. New York: Free Press of Glencoe.

Barnes, Barry. ed. 1972. Sociology of Science: Selected Readings. Harmondsworth, England: Penguin Books.

Edge, David and M. J. Mulkay. 1976. Astronomy Transformed: The Emergence of Radio Astronomy in Britain. New York; London: Wiley.

Gilbert, G. Nigel and M. J. Mulkay. 1984. Opening Pandora's Box: A Sociological Analysis of Scientists' Discourse. Cambridge: Cambridge University Press.

Kuhn, Thomas. 1962. The Structure of Scientific Revolutions. Chicago: University of Chicago Press.

McCloskey, Donald N. 1987. "The Word and the World: Explorations in the Form of Sociological Analysis. (Book Review)." American Journal of Sociology 93(2):467-69.

Mulkay, M. J. 1979. Science and the Sociology of Knowledge. London; Boston: G. Allen \& Unwin.

Mulkay, M. J. 1981. "Action and Belief or Scientific Discourse? A Possible Way of Ending Intellectual Vassalage in Social Studies of Science." Philosophy of the Social Sciences 11(2):163-71.

Mulkay, M. J. 1985. The Word and the World: Explorations in the Form of Sociological Analysis. London: Allen \& Unwin.

Mulkay, M. J. 1991. Sociology of Science: A Sociological Pilgrimage. Milton Keynes: Open University Press.

Mulkay, M. J. 1997. The Embryo Research Debate: Science and the Politics of Reproduction. Cambridge Cultural Social Studies. Cambridge: Cambridge University Press. 